\title{
Comparison of thick-target (alpha,n) yield calculation codes
}

\author{
Ana C. Fernandes ${ }^{1, *}$, Andreas $\mathrm{Kling}^{1}$ and Gennadiy N. Vlaskin ${ }^{2}$ \\ ${ }^{1}$ Centro de Ciências e Tecnologias Nucleares, Instituto Superior Técnico, Universidade de Lisboa, 2695-066 Bobadela, Portugal \\ ${ }^{2}$ Innovation Technology Centre for the PRORYV Project, ROSATOM, 107140 Moscow, Russia
}

\begin{abstract}
Neutron production yields and energy distributions from $(\alpha, n)$ reactions in light elements were calculated using three different codes (SOURCES, NEDIS and USD) and compared with the existing experimental data in the $3.5-10 \mathrm{MeV}$ alpha energy range. SOURCES and NEDIS display an agreement between calculated and measured yields in the decay series of ${ }^{235} \mathrm{U},{ }^{238} \mathrm{U}$ and ${ }^{232} \mathrm{Th}$ within $\pm 10 \%$ for most materials. The discrepancy increases with alpha energy but still an agreement of $\pm 20 \%$ applies to all materials with reliable elemental production yields (the few exceptions are identified). The calculated neutron energy distributions describe the experimental data, with NEDIS retrieving very well the detailed features. USD generally underestimates the measured yields, in particular for compounds with heavy elements and/or at high alpha energies. The energy distributions exhibit sharp peaks that do not match the observations. These findings may be caused by a poor accounting of the alpha particle energy loss by the code. A big variability was found among the calculated neutron production yields for alphas from Sm decay; the lack of yield measurements for low $(\sim 2 \mathrm{MeV})$ alphas does not allow to conclude on the codes' accuracy in this energy region.
\end{abstract}

\section{Introduction}

Alpha-induced neutron production yield data are required in numerous scenarios including the nuclear fuel cycle [1], nuclear safeguards and forensics [2], geological [3] and astrophysical studies [4], underground facilities [5], nuclear fusion [6] and radiation shielding [7]. In addition to thick-target production yields and neutron energy distributions most applications require small or at least reliable estimates for the uncertainty in the yield data.

Modern general-purpose radiation transport simulation codes [8-10] can model particle transport, production of secondaries and particle detection with an overall accuracy in the order of $10 \%$. However their modelling of neutron production is either inaccurate or inexistent at the energy range relevant for most applications, and neutron yields and spectra are extracted more conveniently from evaluated cross-section data.

Various codes have been developed to derive the alpha-induced neutron spectra and production yields due to decay of various radionuclides. In this work we compare the data provided by three codes, and conclude on their accuracy upon comparison with experimental results.

\section{Materials and methods}

\subsection{Overview of the tested codes}

The evaluated codes are: (i) SOURCES-4C [11] developed at Los Alamos National Laboratory, USA and released by the Nuclear Energy Agency data bank; (ii) an application developed at the University of South Dakota, USA - hereafter the USD code - and available online [12]; (iii) the NEDIS-2.0 code [13], developed at the A.A. Bochvar Research Institute of Inorganic Materials, Moscow, Russia. A version of SOURCES-4A with an extended energy range that allows to include most decay alphas was developed at the University of Sheffield, UK and included in the evaluation [14].

All codes calculate thick-target yields by integrating the $(\alpha, n)$ reaction cross sections $(\sigma)$ over the alpha particle range in the target material. The stopping power (s) of alpha particles in the material accounts for their energy loss during transport and the calculation consists of integrating $\sigma(\mathrm{E}) / \mathrm{s}(\mathrm{E})$ between the threshold energy $\left(E_{t h}\right)$ for neutron production and the initial alpha energy $\left(\mathrm{E}_{\alpha}\right)$.

When multiple alpha energies are involved e.g. from radioactive decay, the corresponding yields are summed to derive the total yield.

The yield in multi-element materials is derived from the elemental yields using the Bragg-Kleeman rule that expresses the mass stopping power of the compound or mixture as the sum of the elemental mass stopping

Corresponding author: anafer@ctn.tecnico.ulisboa.pt

C The Authors, published by EDP Sciences. This is an open access article distributed under the terms of the Creative Commons Attribution License 4.0 (http://creativecommons.org/licenses/by/4.0/). 
powers (weighted by the element mass fraction in the material).

The codes differ on their nuclear data libraries, namely for cross sections and stopping powers and on the integration algorithms. When deriving $(\alpha, n)$ energy distributions, different assumptions regarding the neutron angular distribution in the centre of mass system (CMS) are also found.

All codes except USD use the stopping power coefficients from Ziegler's tables/TRIM code [15] which enable to calculate energy-continuous atomic or mass stopping power. USD uses self-developed simulation procedures and extracts stopping powers from the ASTAR program [16]. The latter can be used to calculate alpha stopping power tables for many elements and some compounds based on values of the ICRU-49 report by the International Commission on Radiation Units and Measurements. The results for the stopping power values from ASTAR agree within a few percent with those of TRIM and with measurements [17]. Although ASTAR tables can be made with a very fine mesh, their size is in principle limited for integration in the USD code and may yield some steps or discontinuities.

With respect to cross sections, SOURCES-4C employs experimental data from various sources and calculated data from the nuclear physics code GNASH [18] for Ne and heavier elements. GNASH and therefore SOURCES-4C are limited to a maximum alpha energy of $6.5 \mathrm{MeV}$. However, as both the $(\alpha, \mathrm{n})$ cross sections and the average neutron energy rise with the alpha energy the $6.5 \mathrm{MeV}$ cut reduces the total neutron yield from $(\alpha, n)$ reactions and artificially shifts the neutron spectrum to lower energies. This limitation was overcome in a modified version of SOURCES-4A (previously referred) in which the EMPIRE2.19 nuclear reaction code [19] is used to calculate the cross sections in an extended energy range and include more elements. The reliability of the EMPIRE data was evaluated upon comparison with experimental cross-section data, a few results being reported. A good (but unquantified) agreement is referred, especially at alpha energies below $10 \mathrm{MeV}$.

NEDIS-2.0 employs cross section data, complete and partial (on separate levels of the residual nuclei), from evaluated libraries. The cross sections of the code's standard database have been benchmarked for a vast number of light elements as detailed in Ref. 20, yielding an uncertainty smaller than $10 \%$.

USD employs the nuclear reaction TALYS code to calculate the cross sections. Some benchmarking results and examples are reported for neutron- and protoninduced reactions [21], but we could not find any information regarding the code performance for $(\alpha, n)$ reactions.

The benchmarking status, as reported, for neutron yield calculations varies among the codes. Benchmarking of SOURCES-4C is reported in Ref. 14 and references therein; typical agreement between measured and calculated neutron production yields of $10-20 \%$ were found. NEDIS estimates an uncertainty below $10 \%$ for most materials due to the application of evaluated cross sections that nevertheless remain as the principal contributor to the yield uncertainty [20, 21]. USD quotes a good overall, but unquantified, agreement with experimental values.

As final note, both SOURCES-4C and NEDIS can provide $(\alpha, n)$ data for user-defined alpha energies or combination of alpha emitters, whereas USD is restricted to the ${ }^{238} \mathrm{U}$ and ${ }^{232} \mathrm{Th}$ series in secular equilibrium and to the Sm decay.

\subsection{Evaluated quantities}

In this work homogeneous mixtures are considered, in which the alpha-emitting atoms are embedded and directly adjacent to the target material. The quality of calculated yields was assessed upon comparison with experimental data. Both the total production yields and their energy distributions are investigated.

We considered mostly alpha energies in the 4-9 MeV range, which is representative of common particle accelerators and of actinide decay. The latter consisted mainly of the ${ }^{235} \mathrm{U},{ }^{238} \mathrm{U}$ and ${ }^{232} \mathrm{Th}$ series in equilibrium. Additionally, the low energy of ${ }^{147} \mathrm{Sm}$ decay $(2.248$ $\mathrm{MeV}$, for which there are no yield measurements to our best knowledge) was also included due to the presence of Samarium in some detector components [12].

Only original yield measurements were considered: any cross section integration, yield conversion between elements and compound materials, or extrapolation beyond the experimental alpha energy range were excluded. The treatment of experimental data was restricted to cubic-splines interpolation when deriving yields for intermediate alpha energies, e.g., from isotopes' decay.

\subsection{Experimental data}

Extensive compilations of experimental $(\alpha, n)$ yields can be found and have been discussed in Ref. 22. In this work we have considered:

(i) thick-target yields measured by West and Sherwood [23] as a function of alpha energy (3.5-10 $\mathrm{MeV})$ for various elements $(\mathrm{Be}, \mathrm{C}, \mathrm{Mg}, \mathrm{Al}, \mathrm{Si}, \mathrm{Fe})$ and compounds ( $\left.\mathrm{BeO}, \mathrm{BN}, \mathrm{UC}, \mathrm{UO}_{2}\right)$;

(ii) thick-target yields measured by Bair and Gomez del Campo [24] as a function of alpha energy (3.5-7.5 $\mathrm{MeV}$ ) for $\mathrm{Li}$ and $\mathrm{B}$ which complements the above elemental data. Measurements in $\mathrm{PbF}_{2}$ and $\mathrm{ZnF}_{2}$ were performed in order to derive the $\mathrm{F}$ yield (because the yield contribution from $\mathrm{Pb}$ and $\mathrm{Zn}$ is negligible). However, as the actual results were not reported measurements in $\mathrm{PbF}_{2}(3.5-10 \mathrm{MeV})$ were extracted from Ref. 25;

(iii) thick-target yields measured by Feige et al. [26] as a function of alpha energy for various geological minerals $\left(\mathrm{Na}_{2} \mathrm{CO}_{3}, \mathrm{~K}_{2} \mathrm{CO}_{3}, \mathrm{CaF}_{2}\right)$.

(iv) thick-target yields measured by Gorshov et al. [27] for a vast list of elements and compounds, in the emission spectra of ${ }^{238} \mathrm{U}$ and ${ }^{232} \mathrm{Th}$ decay series.

(v) neutron energy distributions measured by Jacobs and Liskien [28] as a function of alpha energy 
(4-5.5 MeV) for $\mathrm{C}, \mathrm{Mg}, \mathrm{Al}$ and $\mathrm{Si}$ and furthermore $\mathrm{BN}$, $\mathrm{CaF}_{2}, \mathrm{Al}_{2} \mathrm{O}_{3}, \mathrm{SiO}_{2}$ and $\mathrm{UO}_{2}$. We note that data for $\mathrm{BN}$, $\mathrm{CaF}_{2}$ and $\mathrm{UO}_{2}$ are representative of $\mathrm{B}, \mathrm{F}$ and $\mathrm{O}$, respectively;

(vi) neutron energy distributions from $\mathrm{Am}-\mathrm{Be}$ and Am- $\mathrm{Li}$ sources [29, 30], representative of $\mathrm{Be}$ and $\mathrm{Li}$ yields at quasi-monoenergetic $5.480 \mathrm{MeV}$ alphas.

\section{Results}

\subsection{Yield dependence on alpha energy}

Figure 1 shows calculated and measured yields as a function of alpha energy for various elements. The threshold energy $\left(E_{t h}\right)$ is indicated when the $(\alpha, n)$ reaction is endoenergetic.

Measurements from different works are plot allowing to perceive the consistency among the values. The data identified as SOURCES consists of SOURCES-4C results up to $6.5 \mathrm{MeV}$, and of the energy-extended SOURCES-4A in the 6.5-10 MeV energy range. In case the distributions do not match below $6.5 \mathrm{MeV}$, they are discriminated. Although $\mathrm{Fe}$ is not included in the standard version of NEDIS-2.0, yields were calculated using cross sections for the ${ }^{54} \mathrm{Fe}(\alpha, \mathrm{n})$ reaction determined by Houck and by Levkovsii and available in the EXFOR database [31]. The cross section for ${ }^{56} \mathrm{Fe}$ was determined on the basis of the measured neutron yields from Ref. 23.

The results show that SOURCES-4A/C and NEDIS2.0 are able to reproduce the measured yields for most elements within the experimental uncertainties or with small deviations from the experimental values. Important exceptions were found for $\mathrm{C}$ and $\mathrm{Si}$, with a significant overestimation of the yield by SOURCES-4A. In the case of Silicon, SOURCES results start to diverge from measurements at $6.5 \mathrm{MeV}$, which evidences problems in the data employed by SOURCES-4A. For Carbon the SOURCES-4A and $-4 \mathrm{C}$ yields split early at $5 \mathrm{MeV}$, meaning that the data employed by SOURCES-4C was not preserved by SOURCES-4A. For both, $\mathrm{C}$ and $\mathrm{Si}$, the discrepancy with experimental data could be mitigated by normalising the EMPIRE-calculated data to yield measurements, e.g., from Ref. 23. NEDIS and SOURCES yields for Boron divide at $\sim 8 \mathrm{MeV}$, with SOURCES data being coincident with that from Ref. 22 that extrapolates experimental values beyond $7.5 \mathrm{MeV}$.

Yield values for selected compound media are shown in Fig. 2. Besides $\mathrm{UO}_{2}$ and $\mathrm{PbF}_{2}$ which allow to evaluate the data quality for $\mathrm{F}$ and $\mathrm{U}, \mathrm{SiO}_{2}$ is included as an important material in nuclear waste vitrification and a main constituent of geological materials employed in shielding construction. In the case of $\mathrm{PbF}_{2}$, the results of a recent effort to improve the accuracy of cross section data for the ${ }^{19} \mathrm{~F}(\alpha, \mathrm{n})$ reaction [32] were also employed in the NEDIS calculations. The results evidence a good agreement between calculated and experimental yields for $\mathrm{O}$ and $\mathrm{F}$ compounds; the $\mathrm{SiO}_{2}$ yield overestimate by SOURCES reflects that in Si. The new ${ }^{19} \mathrm{~F}(\alpha, \mathrm{n})$ cross section data provides yield values $30-40 \%$ higher than standard NEDIS calculations (in the energy region $>5.5 \mathrm{MeV}$ ) and exhibit a superior agreement with measurements.
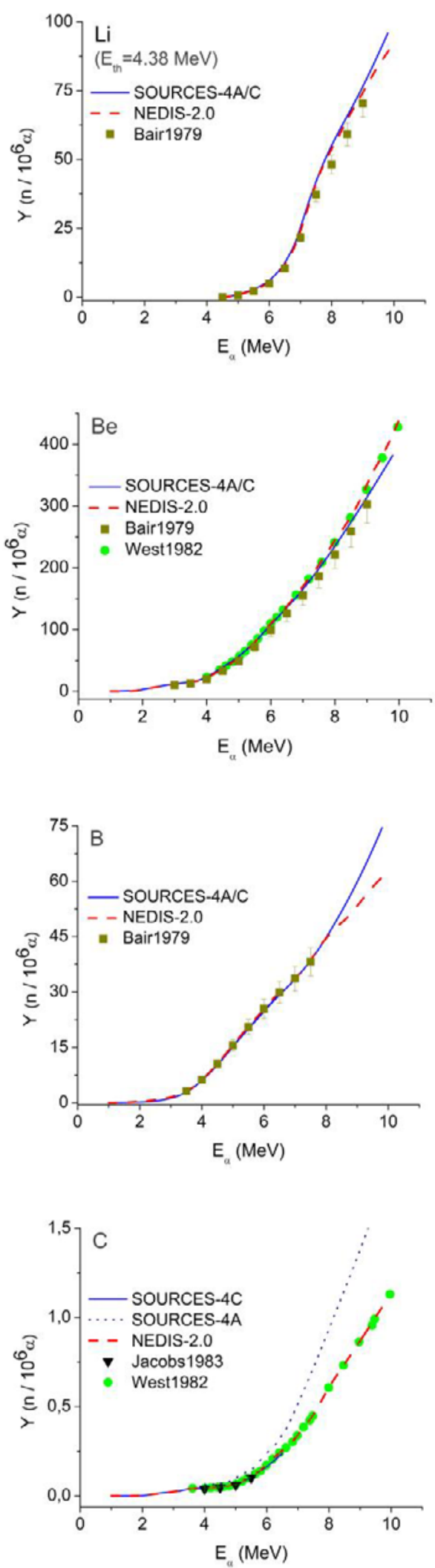

Fig. 1. Calculated and measured $(\alpha, n)$ yields in elemental materials, as a function of alpha energy. References of the experimental data are Bair1979 [24], Jacobs1983 [28], West1982 [23] and Feige1968 [26]. 

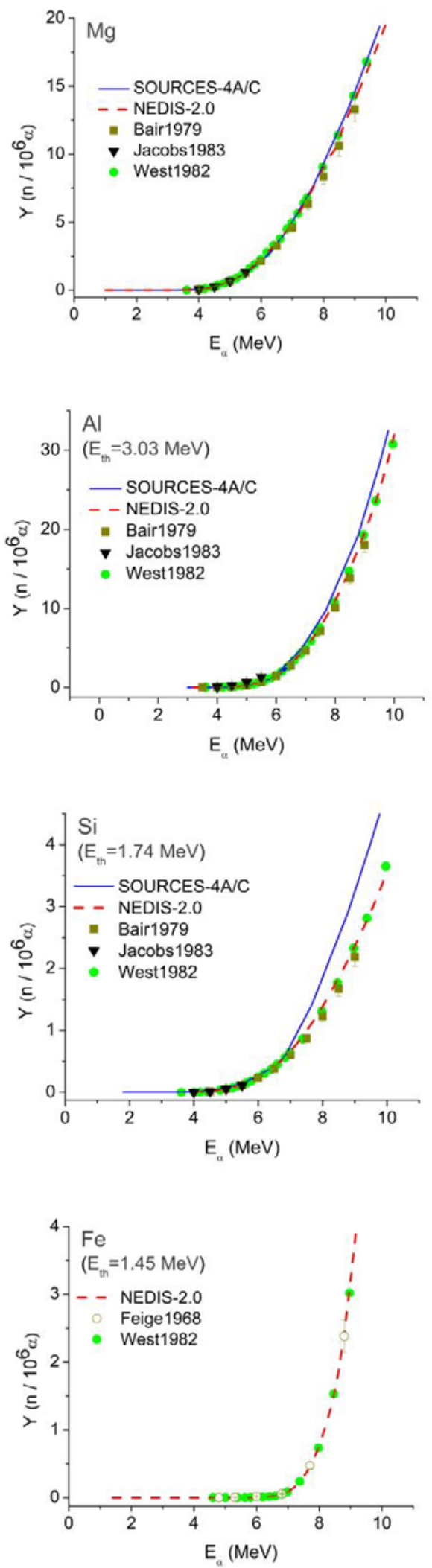

Fig. 1 (cont.). Calculated and measured $(\alpha, n)$ yields in elemental materials, as a function of alpha energy. References of the experimental data are Bair1979 [24], Jacobs1983 [28], West1982 [23] and Feige1968 [26].
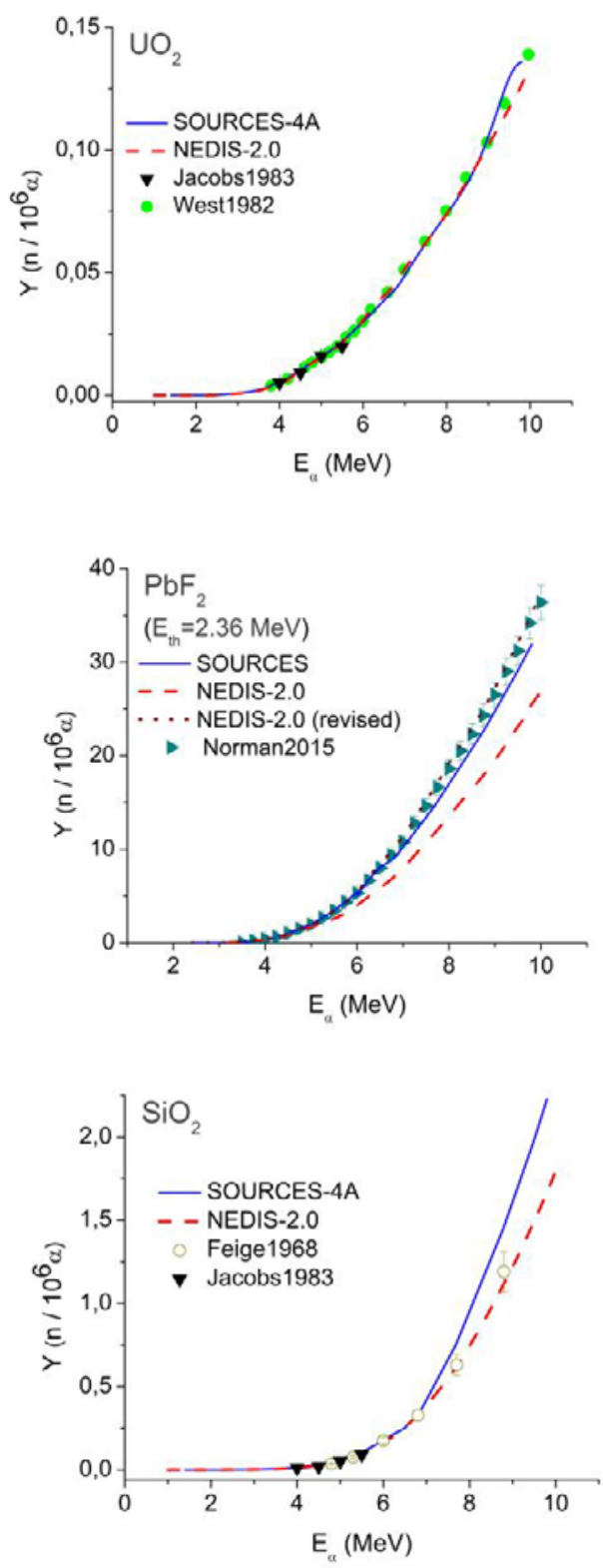

Fig. 2. Calculated and measured $(\alpha, n)$ yields in compound materials, as a function of alpha energy. References of the experimental data are Jacobs1983 [28], West1982 [23] and Feige 1968 [26]. The revised NEDIS yield calculations employ cross section data from Ref. 32.

\subsection{Yields for natural emitters}

We now provide $(\alpha, n)$ yields for the emission spectra of ${ }^{235} \mathrm{U},{ }^{238} \mathrm{U}$ and ${ }^{232} \mathrm{Th}$ decay series in secular equilibrium, and for the decay of Sm. Evaluated decay data (alpha energies and intensities) [33] was used to weight the contribution of each emission line. The energy range and average energies of the decay series (considering emission intensities $>1 \%$ ) are: 4.22-7.39 $\mathrm{MeV}$ and 5.94 MeV for ${ }^{235} \mathrm{U}$; 4.15-7.69 $\mathrm{MeV}$ and 5.36 $\mathrm{MeV}$ for ${ }^{238} \mathrm{U}$; 3.95-8.78 MeV and $6.00 \mathrm{MeV}$ for ${ }^{232} \mathrm{Th}$. The ${ }^{232} \mathrm{Th}$ series is richer in high energies to which correspond therefore larger $(\alpha, \mathrm{n})$ yields. From a similar reasoning, the ${ }^{238} \mathrm{U}$ series displays the smaller yields. 
Tables 1-3 contain measured and calculated yields for the referred decay series. The "experimental values" consist of either cubic-spline interpolation of the measured yields as a function of energy (Section 3.1) or the direct measurements from Ref. 27. Uncertainties are assumed to be at the 1-sigma level, and the following notation is used: $1.23456=1.234 \pm 0.056$ (i.e. the digits in italic indicate the uncertainty in the last digits of the quantity).

With respect to neutron production from Sm, only calculated yields in selected materials are reported in Table 4. Yield values using libraries other than the standard NEDIS (namely the Japanese Evaluated Neutron Data Library, JENDL and the Evaluated Neutron Data File, ENDF [34, 35]) are given for some targets.

Table 1. Measured and calculated neutron yields $\left(n / 10^{6} \alpha\right)$ for the spectrum of the ${ }^{235} \mathrm{U}$ decay series in secular equilibrium.

\begin{tabular}{|c|c|c|c|}
\hline Target & Measured & $\begin{array}{c}\text { SOURCES } \\
-4 A\end{array}$ & $\begin{array}{c}\text { NEDIS } \\
-2.0\end{array}$ \\
\hline $\mathrm{Li}$ & $\begin{array}{c}9.8270 \\
{[24]}\end{array}$ & 11.88 & 10.9577 \\
\hline $\mathrm{Be}$ & $\begin{array}{c}100.017 \\
*\end{array}$ & 120.0 & 1093 \\
\hline B & $\begin{array}{c}24.316 \\
{[24]}\end{array}$ & 26.61 & 24.511 \\
\hline $\mathrm{C}$ & $\begin{array}{c}0.196528 \\
{[23]}\end{array}$ & 0.3070 & 0.201 \\
\hline $\mathrm{Mg}$ & $\begin{array}{c}2.72435 \\
*\end{array}$ & 2.796 & 2.71 \\
\hline $\mathrm{Al}$ & $\begin{array}{c}2.40928 \\
*\end{array}$ & 2.832 & 2.459 \\
\hline $\mathrm{Si}$ & $\begin{array}{c}0.325839 \\
{[23]}\end{array}$ & 0.2286 & 0.323 \\
\hline $\mathrm{BeO}$ & $\begin{array}{c}40.4261 \\
{[23]}\end{array}$ & 44.10 & 40.715 \\
\hline UC & $\begin{array}{c}0.0316848 \\
{[23]}\end{array}$ & 0.04498 & 0.029518 \\
\hline $\mathrm{CaF}_{2}$ & $\begin{array}{c}9.822 \\
{[26]}\end{array}$ & 9.719 & 10.07 \\
\hline $\mathrm{PbF}_{2}$ & $\begin{array}{c}6.1731 \\
{[25]}\end{array}$ & 6.207 & 6.3855 \\
\hline $\mathrm{Na}_{2} \mathrm{CO}_{3}$ & $\begin{array}{l}2.74 \\
{[26]}\end{array}$ & 2.805 & 2.3423 \\
\hline $\mathrm{SiO}_{2}$ & $\begin{array}{c}0.225 \\
{[26]}\end{array}$ & 0.2365 & 0.202 \\
\hline $\mathrm{K}_{2} \mathrm{CO}_{3}$ & $\begin{array}{c}0.228 \\
{[26]}\end{array}$ & 0.07523 & 0.143 \\
\hline $\mathrm{UO}_{2}$ & $\begin{array}{c}0.0323022 \\
{[23]}\end{array}$ & 0.03169 & 0.0322 \\
\hline
\end{tabular}

* references:

Be: 10010 [24]; 110.217 [23]

Mg: $2.73236[23] ; 2.5018$ [24]; 2.6734 [26]

Al: 2.41929 [23]; 2.2411 [24]; 2.4235 [26]

Fe: $0.04651[23] ; 0.04992$ [26]
Table 2. Measured and calculated neutron yields $\left(n / 10^{6} \alpha\right)$ for the spectrum of the ${ }^{238} \mathrm{U}$ decay series in secular equilibrium.

\begin{tabular}{|c|c|c|c|c|}
\hline Target & Measured & $\begin{array}{c}\text { SOURCES } \\
-4 A\end{array}$ & $\begin{array}{c}\text { NEDIS } \\
-2.0\end{array}$ & USD \\
\hline $\mathrm{Li}$ & $\begin{array}{c}6.3544 \\
{[24]}\end{array}$ & 7.375 & 7.1950 & 6.40 \\
\hline $\mathrm{Be}$ & $\begin{array}{c}80.113 \\
*\end{array}$ & 79.93 & 79.624 & 39.5 \\
\hline B & $\begin{array}{l}213 \\
{[27]}\end{array}$ & 18.57 & 19.18 & 14.8 \\
\hline $\mathrm{C}$ & $\begin{array}{c}0.139720 \\
*\end{array}$ & 0.1977 & 0.1376 & 0.120 \\
\hline $\mathrm{Mg}$ & $\begin{array}{c}1.72822 \\
*\end{array}$ & 1.637 & 1.716 & 1.33 \\
\hline $\mathrm{Al}$ & $\begin{array}{c}1.51417 \\
*\end{array}$ & 1.657 & 1.525 & 1.58 \\
\hline $\mathrm{Si}$ & $\begin{array}{c}0.204725 \\
*\end{array}$ & 0.2696 & 0.212 & 0.176 \\
\hline $\mathrm{Fe}$ & $\begin{array}{c}0.05913 \\
*\end{array}$ & - & 0.0563 & 0.0525 \\
\hline $\mathrm{BeO}$ & $\begin{array}{c}31.5630 \\
*\end{array}$ & 29.37 & 29.39 & 14.3 \\
\hline $\mathrm{H}_{3} \mathrm{BO}_{3}$ & $\begin{array}{l}3.15 \\
{[27]}\end{array}$ & 3.157 & 3.2512 & 2.66 \\
\hline UC & $\begin{array}{c}0.0223133 \\
{[23]}\end{array}$ & 0.02913 & 0.020512 & $\begin{array}{r}5.76 \\
\times 10^{-3}\end{array}$ \\
\hline $\mathrm{CaF}_{2}$ & $\begin{array}{c}6.0192 \\
*\end{array}$ & 5.802 & 6.4845 & 4.68 \\
\hline $\mathrm{PbF}_{2}$ & $\begin{array}{c}4.0820 \\
{[25]}\end{array}$ & 3.710 & 4.1440 & 1.49 \\
\hline $\mathrm{NaF}$ & $\begin{array}{c}6.821 \\
{[27]}\end{array}$ & 7.369 & 7.75 & 6.05 \\
\hline $\mathrm{Na}_{2} \mathrm{CO}_{3}$ & $\begin{array}{r}1.73 \\
{[26]}\end{array}$ & 1.660 & 1.4414 & 0.783 \\
\hline $\mathrm{Al}_{2} \mathrm{O}_{3}$ & $\begin{array}{l}0.81 \\
{[27]}\end{array}$ & 0.8437 & 0.782 & 0.860 \\
\hline $\mathrm{SiO}_{2}$ & $\begin{array}{c}0.132 \\
{[26]}\end{array}$ & 0.1550 & 0.13411 & 0.116 \\
\hline $\mathrm{K}_{2} \mathrm{CO}_{3}$ & $\begin{array}{c}0.123 \\
{[26]}\end{array}$ & 0.04783 & 0.09710 & $0 . .265$ \\
\hline $\mathrm{UO}_{2}$ & $\begin{array}{c}0.0231228 \\
{[23]}\end{array}$ & 0.01997 & 0.022811 & $\begin{array}{c}5.48 \\
\times 10^{-3}\end{array}$ \\
\hline
\end{tabular}

* references:

Be: 80.113 [23]; 72.172 [24]; 9213 [27]

C: $0.139620[23] ; 0.174[27]$

Mg: 1.73223 [23]; 1.6011 [24]; 1.62 [26]; 2.14 [27]

Al: $\quad 1.52118[23] ; 1.40970$ [24]; 1.4715 [26]; 1.52 [27]

$\mathrm{Si}: \quad 0.204525[23] ; 0.266[27]$

Fe: $0.07490[23] ; 0.06199[26]$

BeO: 29.3544 [23]; 334 [27]

$\mathrm{CaF}_{2}: 5.710$ [26]; 7.022 [27] 
Table 3. Measured and calculated neutron yields $\left(n / 10^{6} \alpha\right)$ for the spectrum of the ${ }^{232} \mathrm{Th}$ decay series in secular equilibrium.

\begin{tabular}{|c|c|c|c|c|}
\hline Target & Measured & $\begin{array}{c}\text { SOURCES } \\
-4 A\end{array}$ & $\begin{array}{c}\text { NEDIS } \\
-2.0\end{array}$ & USD \\
\hline $\mathrm{Li}$ & $\begin{array}{c}11.9984 \\
{[24]}\end{array}$ & 12.25 & 15.510 & 5.60 \\
\hline $\mathrm{Be}$ & $\begin{array}{c}117.720 \\
*\end{array}$ & 103.7 & 1183 & 35.9 \\
\hline B & $\begin{array}{l}274 \\
{[27]}\end{array}$ & 14.81 & 25.111 & 14.4 \\
\hline $\mathrm{C}$ & $\begin{array}{c}0.230532 \\
*\end{array}$ & 0.2991 & 0.231 & 0.132 \\
\hline $\mathrm{Mg}$ & $\begin{array}{c}3.28042 \\
*\end{array}$ & 2.826 & 3.2112 & 1.72 \\
\hline $\mathrm{Al}$ & $\begin{array}{c}3.08614 \\
*\end{array}$ & 3.282 & 3.31 & 2.39 \\
\hline $\mathrm{Si}$ & $\begin{array}{c}0.433652 \\
*\end{array}$ & 0.4830 & 0.433 & 0.248 \\
\hline $\mathrm{Fe}$ & $\begin{array}{c}0.2657 \\
*\end{array}$ & - & 0.26313 & 0.203 \\
\hline $\mathrm{BeO}$ & $\begin{array}{c}43.4064 \\
*\end{array}$ & 38.03 & 43.214 & 12.9 \\
\hline $\mathrm{UC}$ & $\begin{array}{c}0.0366555 \\
{[23]}\end{array}$ & 0.04339 & $\begin{array}{c}0.0379 \\
20\end{array}$ & $\begin{array}{c}6.38 \\
\times 10^{-3}\end{array}$ \\
\hline $\mathrm{CaF}_{2}$ & $\begin{array}{c}10.5818 \\
*\end{array}$ & 9.136 & 12.58 & 5.82 \\
\hline $\mathrm{PbF}_{2}$ & $\begin{array}{c}6.9735 \\
{[25]}\end{array}$ & 5.813 & 7.9774 & 1.85 \\
\hline $\mathrm{NaF}$ & $\begin{array}{c}12.745 \\
{[27]} \\
\end{array}$ & 12.21 & 15.99 & 7.47 \\
\hline $\mathrm{Na}_{2} \mathrm{CO}_{3}$ & $\begin{array}{l}3.35 \\
{[26]}\end{array}$ & 3.043 & 2.9327 & 0.928 \\
\hline $\mathrm{Al}_{2} \mathrm{O}_{3}$ & $\begin{array}{l}1.82 \\
{[27]}\end{array}$ & 1.651 & 1.675 & 1.29 \\
\hline $\mathrm{SiO}_{2}$ & $\begin{array}{c}0.275 \\
{[26]}\end{array}$ & 0.2641 & 0.252 & 0.157 \\
\hline $\mathrm{K}_{2} \mathrm{CO}_{3}$ & $\begin{array}{c}0.256 \\
{[26]}\end{array}$ & 0.07032 & 0.212 & 0.0300 \\
\hline $\mathrm{UO}_{2}$ & $\begin{array}{c}0.0344641 \\
{[23]}\end{array}$ & 0.02865 & 0.0342 & $\begin{array}{l}6.30 \\
\times 10^{-3}\end{array}$ \\
\hline
\end{tabular}

* references:

Be: 117.820 [23]; 10711 [24]; 12615 [27]

C: $0.230332[23] ; 0.318[27]$

Mg: 3.28943 [23]; 3.0021 [24]; 3.14 [26]; 3.65 [27]

Al: $\quad 3.30940[23] ; 3.04815[24] ; 3.23$ [26]; 3.54 [27]

Si: $\quad 0.433452[23] ; 0.5111[27]$

Fe: $0.2636[23] ; 0.2677$ [26]

BeO: 43.3365 [23]; 475 [27]

$\mathrm{CaF}_{2}: 10.222$ [26]; 11.232 [27]
Table 4. Calculated neutron yields $\left(\mathrm{n} / 10^{6} \alpha\right)$ for the $\alpha$ spectrum from $\mathrm{Sm}$ decay.

\begin{tabular}{|c|c|c|c|}
\hline Target & $\begin{array}{c}\text { SOURCES } \\
-4 \mathrm{C}\end{array}$ & $\begin{array}{c}\text { NEDIS } \\
-2.0 \\
\end{array}$ & USD \\
\hline $\mathrm{Be}$ & 5.510 & 5.50 & 7.89 \\
\hline B & 0.2543 & 0.53 & 1.97 \\
\hline $\mathrm{C}$ & $6.292 \times 10^{-3}$ & $7.3 \times 10^{-3}$ & $1.26 \times 10^{-2}$ \\
\hline $\mathrm{Mg}$ & $2.437 \times 10^{-4}$ & $9.0 \times 10^{-5}$ & $1.87 \times 10^{-4}$ \\
\hline $\mathrm{Si}$ & $1.987 \times 10^{-5}$ & $1.01 \times 10^{-5}$ & $1.18 \times 10^{-6}$ \\
\hline $\mathrm{BeO}$ & 2.005 & 2.00 & 2.85 \\
\hline $\mathrm{H}_{3} \mathrm{BO}_{3}$ & 0.04621 & 0.095 & 0.351 \\
\hline UC & $1.014 \times 10^{-3}$ & $\begin{array}{c}1.08 \times 10^{-3} \\
*\end{array}$ & $6.06 \times 10^{-4}$ \\
\hline $\mathrm{Na}_{2} \mathrm{CO}_{3}$ & $9.019 \times 10^{-4}$ & $8.48 \times 10^{-4}$ & $1.65 \times 10^{-3}$ \\
\hline $\mathrm{Al}_{2} \mathrm{O}_{3}$ & $4.406 \times 10^{-5}$ & $5.89 \times 10^{-5}$ & $2.09 \times 10^{-4}$ \\
\hline $\mathrm{SiO}_{2}$ & $8.096 \times 10^{-5}$ & $6.94 \times 10^{-5}$ & $2.36 \times 10^{-4}$ \\
\hline $\mathrm{UO}_{2}$ & $4.412 \times 10^{-5}$ & $\begin{array}{c}3.17 \times 10^{-5} \\
* *\end{array}$ & $5.25 \times 10^{-5}$ \\
\hline $\mathrm{K}_{2} \mathrm{CO}_{3}$ & $7.425 \times 10^{-4}$ & $\begin{array}{c}7.73 \times 10^{-5} \\
* * *\end{array}$ & $1.25 \times 10^{-3}$ \\
\hline
\end{tabular}

* standard: $1.18 \times 10^{-3}$; JENDL: $1.09 \times 10^{-3} ;$ ENDF: 9.69×1 $0^{-4}$

** standard: $3.55 \times 10^{-5}$; JENDL: $2.39 \times 10^{-5}$;

ENDF: $3.58 \times 10^{-5}$

*** standard: $8.39 \times 10^{-5}$; JENDL: $7.8 \times 10^{-5}$; ENDF: $7.0 \times 10^{-5}$ 
In order to evaluate the accuracy of each code, calculated-to-experimental $(\mathrm{C} / \mathrm{E})$ yield ratios were plot for the ${ }^{238} \mathrm{U}$ and ${ }^{232} \mathrm{Th}$ series (Fig. 3). Elemental target materials were ordered along the $\mathrm{x}$-axis by increasing order of atomic number $(Z)$ in order to identify potential trends with stopping power. In the case of $\mathrm{UO}_{2}, \mathrm{Ca} / \mathrm{PbF}_{2}$ and $\mathrm{Na}_{2} \mathrm{CO}_{3}$ the contributing element is indicated within brackets. The experimental uncertainty and, for NEDIS, the calculation uncertainty are included.
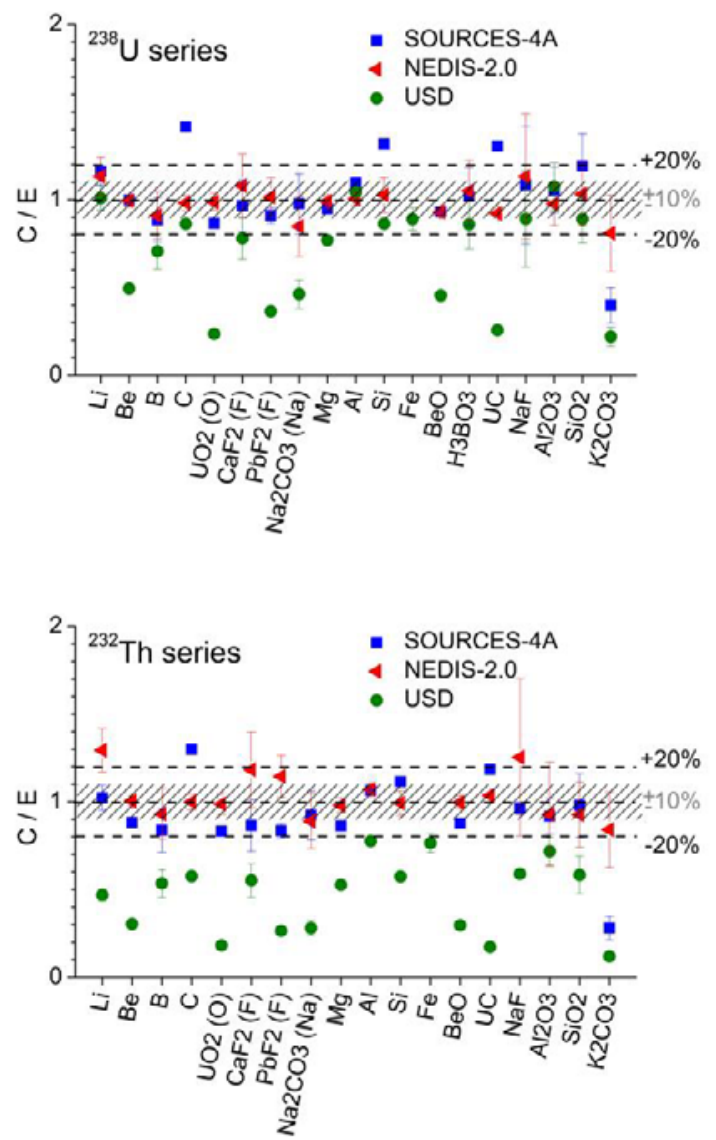

Fig. 3. Calculated-to-experimental $(\alpha, n)$ yield ratios in the alpha spectra of the ${ }^{238} \mathrm{U}$ and ${ }^{232} \mathrm{Th}$ decay series. The shaded area and dashed lines define the $\pm 10 \%$ and $\pm 20 \%$ limits, respectively.

For the ${ }^{238} U$ decay spectrum, both SOURCES-4A and NEDIS agree with measurements within $\pm 10 \%$ for most target materials. SOURCES-4A outliers correspond to yields in $\mathrm{Si}$ and $\mathrm{C}$ (for which SOURCES-4A fails to reproduce the measured yields as a function of energy, Fig. 1) and corresponding compounds, and also to the $\mathrm{K}$ compound which is not available as a target (i.e. only the contribution of $\mathrm{C}$ and $\mathrm{O}$ are accounted for). USD values for elemental materials lie within the $\pm 20 \%$ limits except for $\mathrm{Be}$. However for compounds with heavy elements $(\mathrm{U}, \mathrm{Pb})$ the agreement is degraded, which may indicate some difficulty in including the high stopping power in the yield calculation.

For the ${ }^{232}$ Th series involving higher $\alpha$ energies the findings are not significantly altered, except for a noticeable overestimate of the Li yield by NEDIS. We attribute this to a systematic error in the experimental data, since all yields from the same work lie below those of other works (Fig.1). The accuracy of the USD code is clearly diminished, with an important underestimation of all yields.

The results show that the accuracy of SOURCES and NEDIS is generally in the $\pm 10 \%$ range for decay spectra in the range of that of ${ }^{238} \mathrm{U}$ with a slight degradation to $\pm 20 \%$ as alpha energies increase up to $\sim 10 \mathrm{MeV}$.

\subsection{Neutron energy distribution}

The measured and calculated energy distributions of neutrons produced in $(\alpha, n)$ reactions are represented in Fig. 4 for target elements in the range $Z=3-8$. NEDIS is found to have a high performance in reproducing the structures in the spectra due to the application of evaluated cross sections with respect to the various excited states of the residual nucleus, as well as the anisotropic angular emission in the CMS in particular for ${ }^{7} \mathrm{Li},{ }^{9} \mathrm{Be}$ and ${ }^{13} \mathrm{C}$. This is demonstrated in the neutron distribution for $\mathrm{C}$ and $\mathrm{UO}_{2}$ where the low energy peak corresponds to the first and second excited states of ${ }^{16} \mathrm{O}$ and the first excited state of ${ }^{20} \mathrm{Ne}$, respectively.

Some examples of the neutron energy distribution from compounds in the alpha decay spectra from $\mathrm{U}, \mathrm{Th}$ and $\mathrm{Sm}$ are presented in Fig.5, allowing a comparison with results from the USD code. USD retrieves distributions with sharp features both at low and high alpha energies that are not realistic. The example of Sminduced neutrons in $\mathrm{UO}_{2}$ shows that USD does not convolute the contribution by the first excited states of ${ }^{20} \mathrm{Ne}$ and ${ }^{21} \mathrm{Ne}$ (both extending up to $1.0 \mathrm{MeV}$ neutron energy) and the ground state of ${ }^{21} \mathrm{Ne}$ (maximum neutron energy of $1.4 \mathrm{MeV}$ ) leading us to suppose that the accounting of the slowing down process of alpha particles is insufficient.

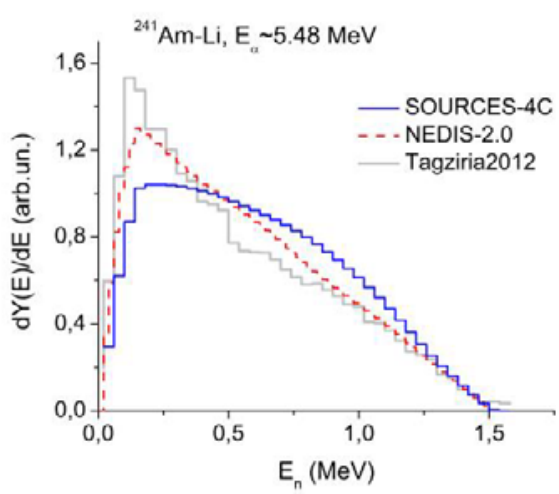

Fig. 4. Calculated and measured energy distributions of $(\alpha, n)$ neutrons induced by quasi-monoenergetic alphas in materials having a single element responsible for the neutron production. 

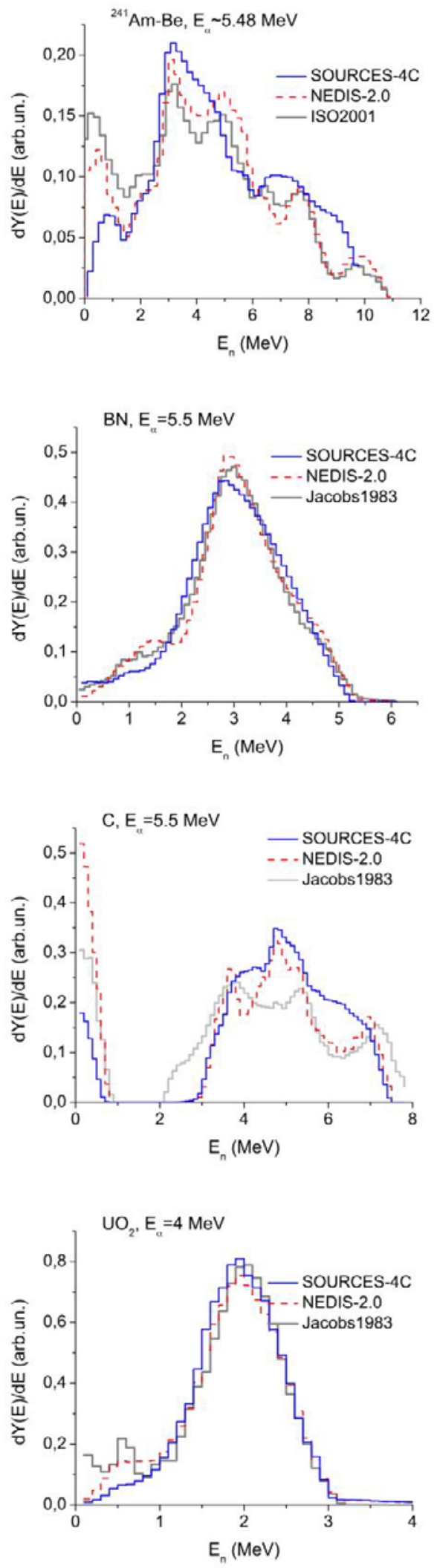

Fig. 4 (cont.). Calculated and measured energy distributions of $(\alpha, n)$ neutrons induced by quasi-monoenergetic alphas in materials having a single element responsible for the neutron production.
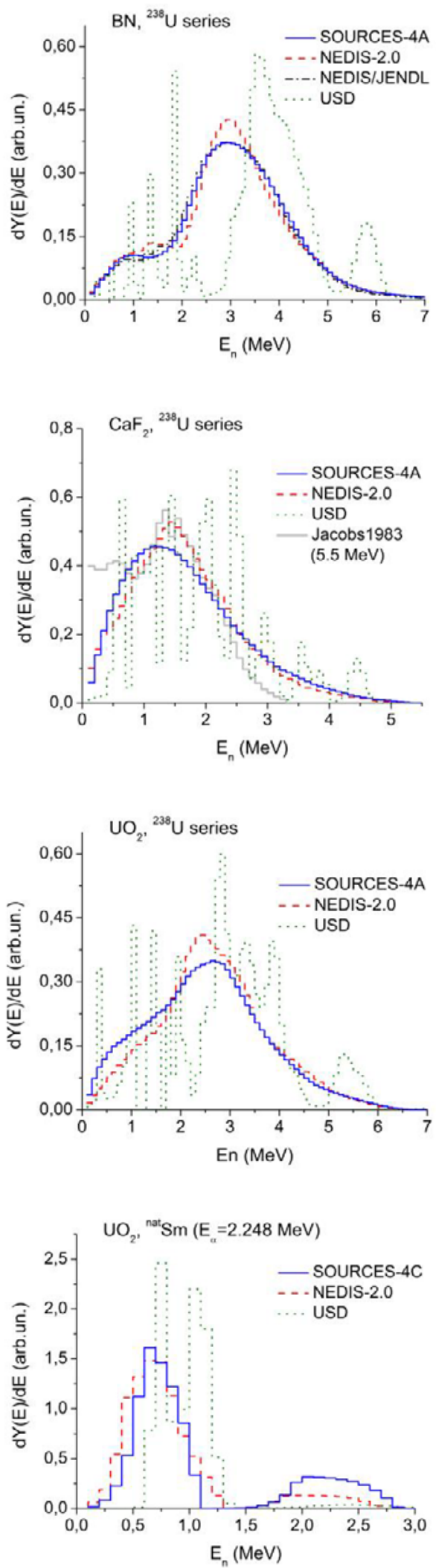

Fig. 5. Calculated energy distributions of $(\alpha, n)$ neutrons induced by the ${ }^{238} \mathrm{U}$ decay series and from $\mathrm{Sm}$. 


\section{Conclusions}

From the three $(\alpha, n)$ yield calculation codes evaluated in this work, SOURCES and NEDIS were found to reproduce total yield measurements within \pm 10 $20 \%$ for most materials - larger limits corresponding to higher alpha energies. Beyond $6.5 \mathrm{MeV}$ alphas, the extended-energy version of SOURCES-4A produces yields significantly larger than measured for $\mathrm{Si}$ and $\mathrm{C}$. The neutron energy distributions calculated by the two codes agree well with measurements, with an improved performance of NEDIS regarding the description of the contribution by the various excited states of the residual nucleus.

For moderate (4-6 MeV) alpha energies, neutron yields extracted by the USD code for elemental materials are generally in good agreement $( \pm 20 \%)$ with measurements. The situation is deteriorated in compound materials with heavy elements, and for higher energies (up to $9 \mathrm{MeV}$ ), with an important underestimation of the neutron yields by the code. The neutron energy distributions display artefacts that are probably created by an insufficient accounting of the alpha particle slowing-down process. However, it may turn out that these features are not relevant to the process under investigation, namely when neutron moderation is important leading to their spreading [36].

A large discrepancy was found for the neutron production yield induced by Sm decay alphas.

The materials considered in this work are only those for which yield measurements were known. Although we believe that the conclusions from this work are generally applicable, the few exceptions that were found lead to the recommendation that distinct code+material+emitter combinations should be subject to an assessment by the user previous to application.

\section{Acknowledgements}

We thank Vitaly Kudryavtsev (University of Sheffield) for offering the version of SOURCES-4A evaluated in the present work.

This activity was supported by Fundação para a Ciência e Tecnologia (Portuguese Ministry of Science) via grant $\mathrm{IF} / 00628 / 2012 / \mathrm{CP} 0171 / \mathrm{CT} 0008$ and by projects UID/Multi/04349/2013 and PTDC/ EEI-ELC/2468/2014.

\section{References}

1. I. Crossland, Nuclear Fuel Cycle Science and Engineering (Woodhead, Cambridge, 2012)

2. D. Reilly, N. Ensslin, H. Smith, S. Kreiner, Passive Nondestructive Assay of Nuclear Materials, US Nuclear Regulatory Commission report NUREG/CR-5550 (US Government Printing Office, Washington DC, 1991)

3. Isotope Methods for Dating Old Groundwater (IAEA, Vienna, 2013)

4. A. Coc, F. Hammache, J. Kiener, Eur. Phys. J. A 51, $34(2015)$
5. J.A. Formaggio, C.J. Martoff, Annu. Rev. Nucl. Part. S. 54, 361 (2004)

6. A. Kaplan, J. Fusion En. 32, 382 (2013)

7. T. Nakamura, L. Heilbronn, Handbook on Secondary Particle Production and Transport by High Energy Heavy Ions (World Scientific, Singapore, 2006)

8. D.B. Pelowitz, MCNPX User's Manual Version 2.7.0 LA-CP-11-00438 (Los Alamos National Laboratory, Los Alamos, 2011)

9. J. Allison, K. Amako, J. Apostolakis, et al., IEEE Trans. Nucl. Sci. 53, 270 (2006)

10. T.T. Böhlen, F. Cerutti, M.P.W. Chin, et al., Nucl. Data Sheets 120, 211 (2014)

11. W.B. Wilson, R.T. Perry, W.S. Charlton et al., Radiat. Prot. Dosim. 115, 117 (2005)

12. D.-M. Mei, C. Zhang, A. Hime, Nucl. Instrum. Methods A 606, 651 (2009). Data available at http://neutronyield.usd.edu

13. G.N. Vlaskin, Yu.S. Khomyakov, V.I. Bulanenko, At. Energ. 117, 357 (2015)

14. V. Tomasello, V.A. Kudryavtsev, M. Robinson, Nucl. Instrum. Methods A 595, 431 (2008)

15. J.F. Ziegler, J.P. Biersack, M.D. Ziegler, SRIM: The Stopping and Range of Ions in Matter (Srim, Chester, 2015). Data available at http://www.srim.org

16. M.J. Berger, J.S. Coursey, M.A. Zucker, J. Chang, ESTAR, PSTAR, and ASTAR: Computer Programs for Calculating Stopping-Power and Range Tables for Electrons, Protons, and Helium Ions, v.1.2.3 (National Institute of Standards and Technology, Gaithersburg, 2005). Data available at http://physics.nist.gov/Star

17. H. Paul, A. Schinner, Nucl. Instrum. Methods B 227, 461 (2005)

18. P.G. Young, E.D. Arthur, M.B. Chadwick, Report LA-12343-MS (Los Alamos National Laboratory, Los Alamos, 1992)

19. M. Herman, R. Capote, B. Carlson et al., Nucl. Data Sheets 108, 2655 (2007)

20. V.A. Vukolov, F.E. Chukreev, At. Énerg. 62, 232 (1987)

21. www.talys.eu/documentation/

22. R. Heaton, H. Lee, P. Skensved, B.C. Robertson, Nucl. Instrum. Methods A 276, 529 (1989)

23. D. West and A.C. Sherwood, Ann. Nucl. Energy 9, 551 (1982)

24. J.K. Bair, J. Gomez del Campo, Nucl. Sci. Eng. 71, 18 (1979)

25. E.B. Norman, T.E. Chupp, K.T. Lesko, et al., Appl. Radiat. Isotopes 103, 177 (2015)

26. Y. Feige, B.G. Oltman, J. Kastner, J. Geophys. Res. 73, 3135 (1968)

27. G.V. Gorshov, O.S. Tsetkov, Sov. Atom. Energy 14, 550 (1964)

28. G.J.H. Jacobs, H. Liskien, Ann. Nucl. Energy 10, 541 (1983)

29. Reference Neutron Radiations (Part 1), ISO 8529-1 (International Standards Organisation, Geneva, 2001) 
30. H. Tagziria, M. Looman, Appl. Radiat. Isotopes 70, 2395 (2012)

31. Experimental Nuclear Reaction Data. Available from, e.g., the IAEA Nuclear Data Section at https://www-nds.iaea.org/exfor/exfor.htm

32. W.A. Peters, M.S. Smith, S. Pittman et al., $A$ kinematically complete, interdisciplinary, and coinstitutional measurement of the $19 F(\alpha, n)$ cross section for suclear safeguards science, INL/EXT16-38791 (Office of Scientific and Technical Information, Oak Ridge, TN, 2016). Available at https://www.osti.gov/scitech/servlets/purl/1263500

33. J.K. Tuli, Nuclear Wallet Cards, 2011. Available at http://www.nndc.bnl.gov/nudat2/

34. T. Murata, H. Matsunobu, K. Shibata, Evaluation of the $(\alpha, x n)$ Reaction data for JENDL/AN-2005, JAEA-Research 2006-052, Japanese Atomic Energy Agency, 2006.

35. M.B. Chadwick et al., Nuclear Data Sheets 112, 2887 (2011)

36. A.C. Fernandes et al., this volume. 